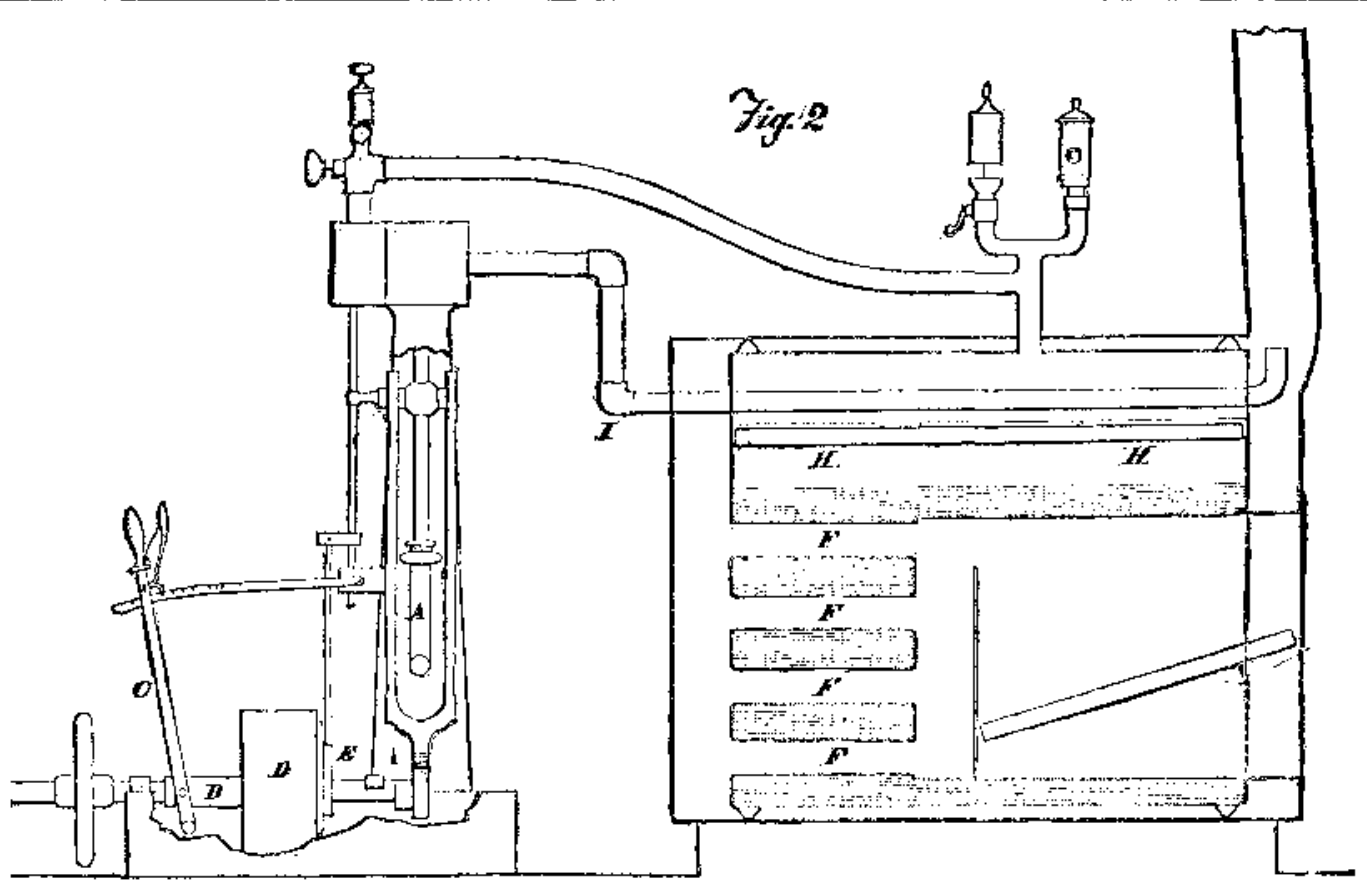

It will be seen from the model exhibited and from the diagrams that the apparatus we employ to carry out our an ordinary floating dock inverted. It is sufficiently large to be submerged over the vessel intended to be raised and entirely to cover it. The breadth inside must therefore be greater or less, according to circumstances.
The two sides of the dock are each constructed in one conThe two sides of the dock are each constructed in one con-
tinuous length and form two hollow box girders; their cross section is tringular as shown at $a a$ in the diagrams, the
apex being downwards and forming a knife.ed ge intended to rest at the bottom-the two sides are connected together at
the top by a number of transverse box girders $b \quad b \quad b$ placed at suitable distances apart, adjusted according to the position of the masts or other obstructions on the deck of the vessel.
These girders are very firmly attached to the sides by numerous and powerful bolts, allowing them to be shifted laterally, and also allowing the sides of the dock to be placed nearer together or further apart, according to the breadth of the
vessel to be lifted-these adjustments are of course effected in harbor before proceeding to the scene of operations. At the four corners of the dock rise four cylindrical
du columns of large diameter (say $20 \mathrm{ft}$. more or less), the tops
of which are always considerably above water, even when of which are always considerably above water, even when
the dock is submerged over a sunken vessel. These columns rise from the transverse girders at the ends of the dock, and they are braced together in pairs and connected by a aridge.

They contain the engines, pumps, and machinery, and to give them greater strength they are, up to a certain height, made double, that is to say, they consist of two concentric ular com-

The whole structure is built of hollow riveted ironwork, and when empty is extremely buoyant, the sides alone beiry
more than sufficient to float the whole. When it is dlesired to submerre the dock over a vessel, water is admitted first
into the siages of the dock and subsequently into some of the transverse rirders, and if necessary into the vertical cylin. ders; the dock is thus all -the operation is further continued until the dock surface over the vessel, either resting upon its deck, or the knife edges of the sildes resting upon the ground-as shown in Fig.
3 . Assuming for the moment that the vessel is upright and 3. Assuming for the moment that the vessel is upright and
free from any accumulation of and it becomes necessary to grip the vessel. This is effected in the following manner: A number of grapnels or curved iron clutches, fitting approximately to the sides of the vessel, are hinged at the top
to the sides of the dock along its whole length. They are each $10 \mathrm{ft}$. or $12 \mathrm{ft}$. broad, constructed of hollow wrought iron plate, and are of great strength, during the submerg.
ence theylie back close against the sides of the dock. Each ence they lie back close against the sides of the dock. Each
of these clutches can be thrown forward at pleasure, by the inflation of a large air bass secured to its back and retsting behind it against the side of the dock. A single pair of thrown forward and caused to grip the vessel a a second pair is then similarly brought into bearing, and the remaining pairs in succession; each pair of clutches, as the latter take their grip, is held in position by ratchets and pawls behind
in such a manner that the clutches cannot be forced back in such a manner that the clutches cannot be forced back
again ; this is to give them additional support when the the curve given to the clutch gives it a secure bearing be.
neath the bilges of the vessel. at the stem and stern air bags without clutches press up beneath the vessel and afford an additional surport; in this condition of things it is evident
that the dock anld the vessel are firmly united, so as to form that the dock and the vessel are firmly united, so as to form
practically one structure, and the buoyancy of the bags alone practically one structure, and the buyancy of the bags alone
will in many cases be sufficient to cause the whole structure to begin to rise; should they not do so, water is forced out of the cross girders, and if necessary ont of the hollow sides, until the vessel rises; as soon as it begins to float it would
come entirely to the surface were it not that the four large come entirely to the surface were it not that the four large cylinders as they emerge from the water reduce the
buoyancy and so prevent the dock from rising too suddenly. buoyancy and so prevent the dock from rising too suddenly. the water upon them is diminished and their internal pressure is increased; in order to relieve this they are provided with the usual pressure valves, opening outwards and adjusted by springs to such a pressure as is deemed best for gripping the vessel; this pressure can never be exceeded, as the surplus air escapes through the valves into the sides of
the dock, or, if its buoyancy is not wanted, into the open the dopk

ENGINE AND BOILER STEAM LAUNCH "FLIRT."

The engines and air pumps are of very great power, so as markable energy, making the air thick with spray, but with able scale ; moreover, almost all the plans that have been to perform their functions rapidly, and are four in number, skillful stecrint and occasional "slowing," no water was adopted have been dependent on the aid of divers. These! situated one in each of the four corner cylinders, and pipes

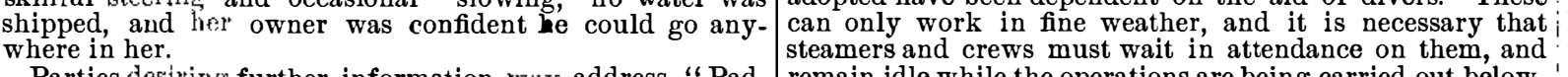
where in her. Parties desiring further information may addre
dlefast," No. 49 East $28 t h$ Street, New Yorls city.

RAISING SUNKEN VESSELS.

On a Practical Method of Raising Sunken Vessels.* By Latimer Clark, C.E.

THE raising of sunken vessels has been at all times a ques. tion of great interest to the maritime world, and the loss of the Vanguard, has recently drawn an unusual amount of
public attention to the subject. Having, in conjunction public attention to the subject. Having, in conjunction
with my partner, Mr. John Standfleld, given great considerawith my partner, Mr. Mohn Standtifled, given great considera-
tion to the matter, we have ventured to bring our plans to tion to the matter, we have entured to bring our plans to
the notice of the Institution of Naval Architects, in the hope that they may be deemed worthy of their examination
and that their merits or defects may be fully discussed. The plans which have been proposed for effecting this object are very various, and while many of them are perfectly impracticable, others are marked by great ingenuity. It
would be outside the scope of this paper to attempt any detailed mention of them, but there is one characteristic they effect their object in a makeshift manner, the operations being performed piecemeal. They do not provide, as they
ought, for the construction of some complete and powerful apparatus which can, with slight adjustments, be made applicable to vessels of all sizes, sunk in various positions an depth, but they are more usually of such a character that
each case has to be specially considered and dealt with.; it naturally follows that the appinatustus designed to meet one we consider, chiefly from this cause that wreck-salvage as a
business has never come into existence on a large and profit remain idle while the operations are being carried out below,
and the submarine attachments are being made, much time and the submarine attachments are being made, much time
is wasted, and the cost of such operations becomes very seri is wasted, and the cost of such operations becomes very seri-
ous and in many cases prohibitory. The depth to which divers can descend and work effectively is, moreover, very limited; and, where masts and rigging are in the way, the pay is necessarily demanded; it is true that jointed diving resses have been devised, with a view to take the pressure
wholly or partially off the diver; but, apart from the stiffness of the joints and the difficulty of working effectively in such rigid dresses, the principle of the well-known Bourdon's pressure-gauge must intevitably come into play and the body or limbs once bent could orlyy be straightened gat at all

Very generally, too, the plans proposed involve the pasage of chains and ropes beneath the vessel, or the attach operation of much difficulty; and there is also great difficulty in such cases in equalizing the strain on several attach ments. Lastly, when air bags are employed, the tendency
of the air to expand as the vessel lifts causes it to come the surface with inconvenient rapidity and dangerou Mr. Standfield and I, having studied the subject de novo, ave long since arrived at the conclusion that ship-raisin ine them by a rush of water as just described; a second pair i rge enough and powerful enough to grasp the vessel bodily . are caused to grip in the same way, and so on till the whole rom the outside without the intervention of ropes or chains, . boiler plate work, have also orifices at their points through ard without the assistate of and without the assistance of divers. The idea of thus deal- which powerful jets of water are forced in order to clear
ing with a vessel is not new, and it had in fact been previ- their way through the sand, or if preferred they mayy be used (a)

- Paper read before the Institution of Naval Architects. he dock; each is of course provided with a pressure indiator, as the pressures are sometimes excessive, amounting pumps are duplicated and so arranged that they can either in conjunction or can each work separat chamber at $35 \mathrm{lbs}$. or $40 \mathrm{lbs}$. pressure, out this chamber at full pressure, even in ordinary use arge space is devoted to air chambers, in which a store of oo that the grippers, for example, can be closed at a mos notice.

We will now suppose that instead of the vessel lying in Wear water it has sunk into the sand or mud, or become surdges of the sides will rest on the sand in some uneven pos of arder to afford means for removing this sand the bottom compartment has a number of holes close to the lower edge compressed air is suddenly turned upon the water, which drives it out of the apertures with great violence, stirring up sand and washing it away, and allowing the dock to ettle down to a lower level untilit either rests on the bottom or bears on the deck of the vessel, as shown in Figs. own in Fir 3 , the sand being driven our assand pumps, water and sand being sucked in in front an
discharged behind.
When the vessel does not lie on an even keel the dock has 
to be lowered in a slanting position, Fig. 1, by admitting afloat, any adjustment of width and position may be equally marvelous that the bearings should have been allowed water at one side and not at the other-when passed over the $\begin{aligned} & \text { affected. } \\ & \text { end }\end{aligned}$ hull of the vessel she has clutched temporarily, and by giv I have thus described as briefly as possible the construc- know when the screw of the Thetis was last lifted, and who

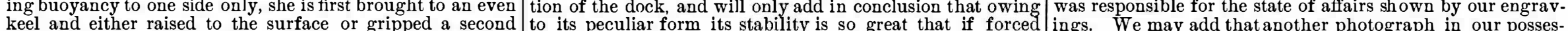
time in her upright position. The vessel when raised is down purposely on to its beam ends it would right itself in- sion shows that the worm employed for turning the engines floated away to a tidal harbor and repaired or broken up. In stantly, and with great power. If sunk over a vessel only by hand.had been subjected to extremely severe wear, the the case of a vessel with a hole in her sides or bows, such as the four cylinders would be above water, and from their engines requiring, we understand, enormous power to move that in the Vangard, an attempt would of course be made small area and great strength they would withstand the at all, a fact which ought to have drawn attention to someto fit an air bag directly over the aperture, and as the dock heaviest storms without danger or injury. In raising a thing being amiss. Altogether, so far as the information at pumped out of her compartments while she was being towed have to be made ; she is supported under the bow and stern of $\mathrm{H}$. M. S. Thetis is the reverse of creditable to all conto port.
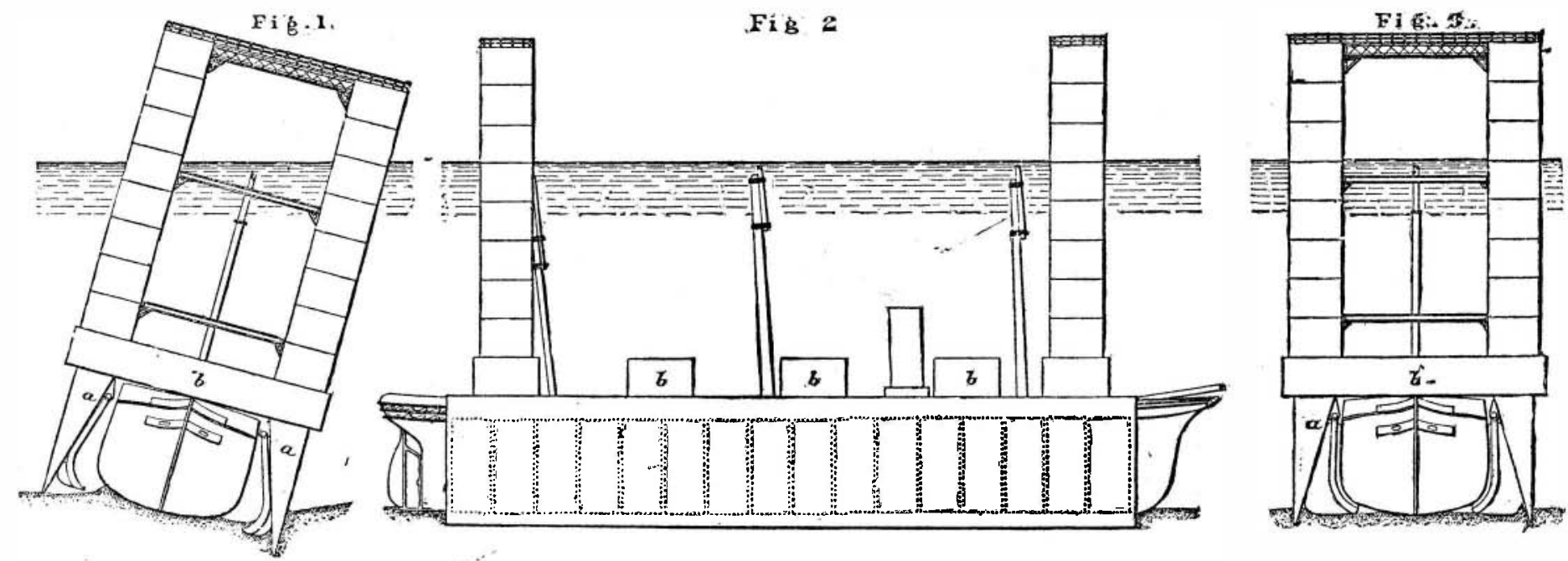

CLARK \& STANDFIELD'S IMPROVED METHOD OF RAISING SUNKEN VESSELS.

We may now consider the degree of pressure required on
he the bags to give an effective grip. - A vessel drawing $20 \mathrm{ft}$. of water has, when afloat, an upward pressure of about 10
lbs. per square inch over her whole bottom surface. Disre garding her loss of weight when in water, and assuming that the air bags bear against over one-half and support the whole weight, we should require a pressure this assumes that the powerful framed iron grippers support no portion of her weight, whereas they are strong enough
to support the vessel without assistance; the weight is thereto support the vessel without assistance; the weight is there-
fore borne partly by the grippers and partly by the upward pressure of the air bags. The bags are made of several easily able to withstand a pressure of $30 \mathrm{lbs}$. or $40 \mathrm{lbs}$. per square inch, or if inclosed in netting a much higher press ure. They are protected from injury by stout matting or thick rope netting.

dock contain a passage running alon

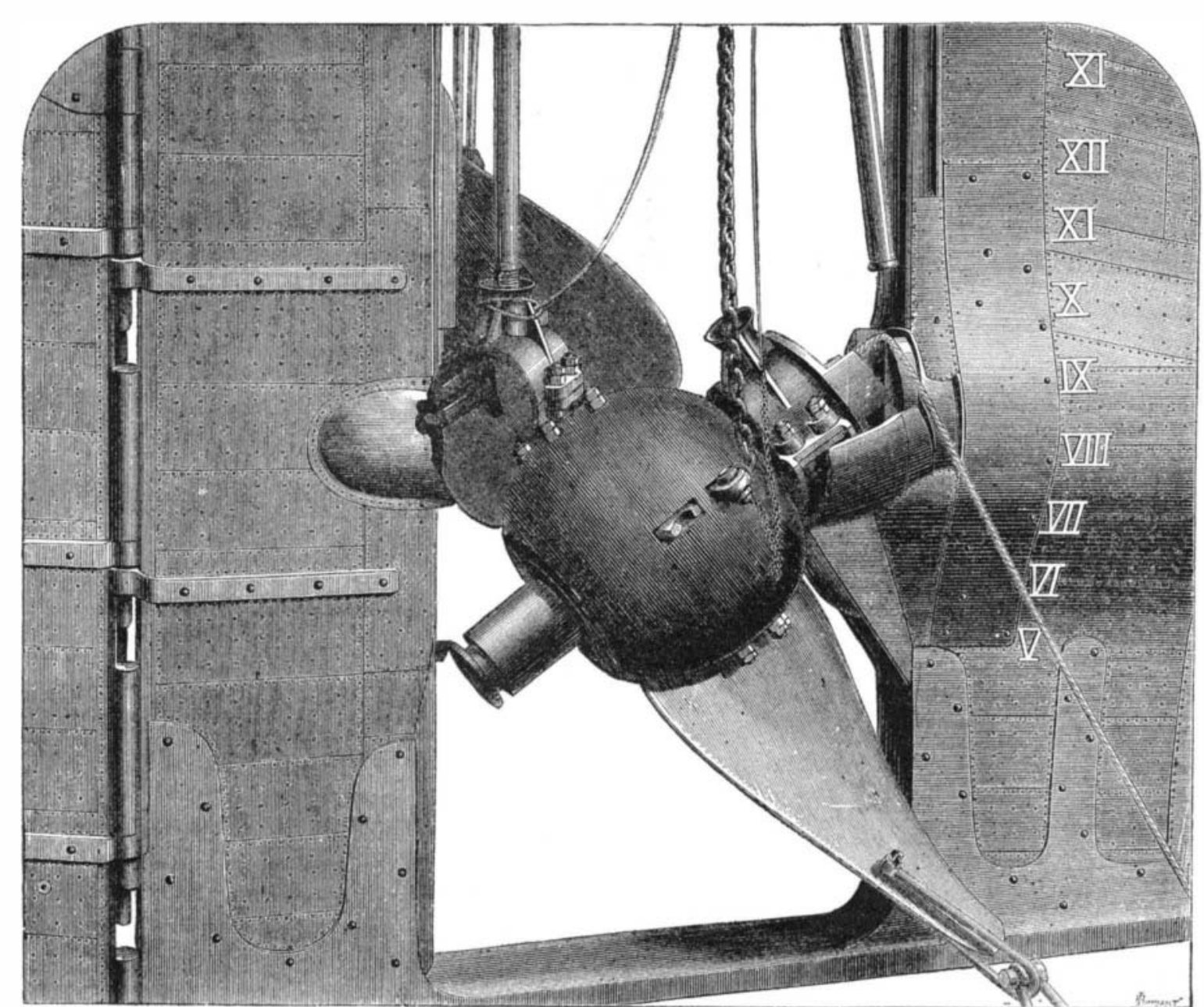
ear to recoup the value many times over.-Engineering. "THETIS,"
PUMP PROPULSION

the strain, the lift in fact takes place along the whole of her length trom stem to stern. The operation under he apparatus ought in average weather to raise at least two hips every week. It is obvious that the depth at which the ation of the apparatus described; on the contrary, such a apparatus could very well raise vessels sunk at twice that uard would probably repay the entire cost, and the salvage
use alue of the property recoverable around the shores of the

PROPELLER AND PROPELLER SHAFT OF THE

H. M. S. Tuents was recently disabled whilst in the the be With with the stem one each side about a foot above the flush With sixty pounds of steam in the boiler the pump makes of water forcibly minute, each revolution sending a stream To go ahead, the water is driven through the stern nozzles, and vice verse and so the boat is pushed on.

\section{CORROSION OF PROPELLERS}

A CURIOUs fact respecting the corrosion of the cast.iron propeller blades of all transatlantic steamers was recently Illustrated by the exhibition of a screw blade before the much corroded, but the thrust side not at all. The at one part was very deeply pitted, but a line of about an inch and a half from the outer edge was not at all corroded. venience in shifting and through which, of course the water passes, is not corroded in its interior; but the surface
of the blade adjacent to this hole, under the line of the cur.

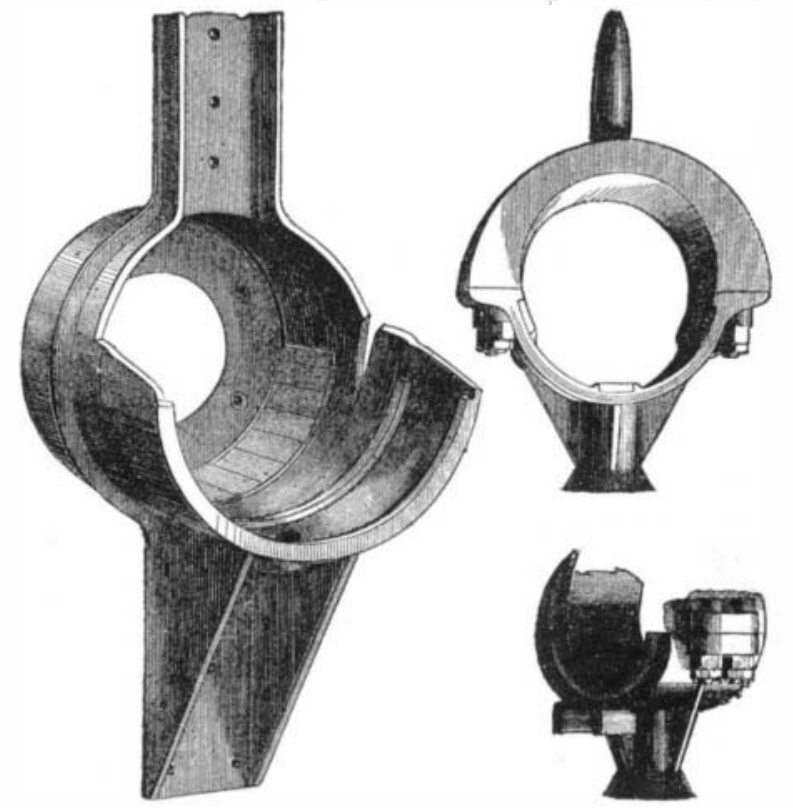

PROPELLER AND PROPELLER SHAFT BEARINGS OF H. M.S. THETIS.

vals, so that the operator, provided with a powerful light $\mid$ towed into Malta to be there docked and overhauled. One rent which issues from the hole, is pitted. Also the blades held against one of them and looking through the other, can of our engravings has been prepared from a photograph of of all the propellers of all transatlantic vessels laid up at the

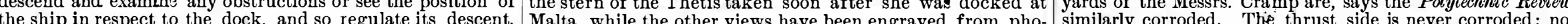
By means of these passages one is enabled to get from tographs of the shaft bearings, etc., taken aftertheir removal are the blades of coastwise steamers so affected.

column to column, and in fact all around the dock without from the vessel.

It will be seen from our iliustrations that the Thetis was In order to adjust the distance asunder of the sides and fitted with a lifting screw and that the outer bearing had THE owners of the Great Eastern are, it is said considerthe position of the top girders, the whole dock is floated ou been allowed to wear completely through, the outer end of frigerating chamber for the conveyance of American meat. rest on ework in harbor, of such a height that the girders the shaft then falling, and the propeller being only prevented The trade in meat, which is being developed not only with \begin{tabular}{l|l} 
rest on the frame at the same time as the sides of the dock from going to the bottom by catching at the stern post. the United States, but also with Brazil, promises to open a \\
rest on the bottom ; by unfastening the ends of the girders \\
Looking at the photograph, it appears marvelous that the wide field of usefulness-a trade which will generally pro-
\end{tabular} at opposite sides alternately, and keeping the sides nearly propeller should not have been completely lost, while it is vide the great vessel with a full load. 